\title{
Stability of SARS-CoV-2 RNA in Viral Lysis Buffer Stored at Different Temperatures
}

\author{
Nagaraj Perumal ${ }^{1, \odot}$ Rajeev Kumar Jain ${ }^{1} \quad$ Rakesh Shrivastava ${ }^{2} \quad$ Jaya Lalwani ${ }^{2}$ Deepti Chaurasia ${ }^{2}$
}

${ }^{1}$ State Virology Laboratory, Gandhi Medical College, Bhopal, Madhya Pradesh, India

2Department of Microbiology, Gandhi Medical College, Bhopal, Madhya Pradesh, India

Address for correspondence Nagaraj Perumal, MSc, PhD, Scientist B, State Virology Laboratory, Gandhi Medical College, Bhopal 462001, Madhya Pradesh, India (e-mail: micronaga07@gmail.com).

\begin{abstract}
Keywords

- RNA

- SARS-CoV-2

- viral lysis buffer

Objectives The present COVID-19 pandemic resulted in an increased need for molecular diagnostic testing. Delay in the specimen processing and suboptimal storage of suspected samples in laboratories leads to degradation of SARS-CoV-2 viral RNA. Viral lysis buffers from RNA extraction kits have the potential to stabilize RNA. Hence, this study aimed to investigate the stability of SARS-CoV-2 RNA in viral lysis buffer at different temperatures and time periods.

Materials and Methods Aliquots of samples with known SARS-CoV-2 RNA were processed in viral lysis buffers simultaneously, stored separately at 2 to $8^{\circ} \mathrm{C}$ and 22 to $28^{\circ} \mathrm{C}$ for 24 hours, 48 hours and 72 hours. SARS-CoV-2 viral RNA was extracted from each aliquot and analyzed using multiplex real-time PCR.

Results SARS-CoV-2 RNA in samples placed in viral lysis buffer was stable for 48 hours at both 2 to $8^{\circ} \mathrm{C}$ and 22 to $28^{\circ} \mathrm{C}$ temperatures. Slight decline in the viral RNA quantity was found on aliquots tested after 48 hours of both the temperatures.

Conclusions Viral lysis buffer maintains the integrity of SARS-CoV-2 RNA for up to 48 hours even at room temperature and supports delayed diagnosis with an overwhelming sample load in testing laboratories.
\end{abstract}

\section{Introduction}

The recent emergence of SARS-CoV-2 leads to an ongoing global health emergency. ${ }^{1,2}$ During this pandemic, the incidence of cases is increasing rapidly. This resulted in an increased need for diagnostic testing, using real-time PCR assays, by targeting a set of different genes of the SARSCoV-2 virus (ORF1ab, open reading frame $1 \mathrm{a}$ and b 226, $\mathrm{N}$-gene [the nucleocapsid protein], E-gene [envelope protein], S-gene [spike protein] and RdRp gene [RNA-dependent RNA polymerase]). ${ }^{3}$ Presently, testing laboratories are facing multiple challenges on different fronts, including a sudden increase in sample load, which leads to delay of the specimen

DOI https://doi.org/ 10.1055/s-0040-1722551 ISSN 0974-2727. processing and results in detection failure due to viral RNA degradation. ${ }^{4}$ This leads to developing newer innovative strategies without compromising the quality of testing outcome as well as biosafety. In this present situation, processing specimens immediately and storing them under optimal conditions is not always possible. RNA extraction kits are provided with the viral lysis buffer and used commonly for their intended purpose of lysing cell, inactivating RNases and stabilizing RNA during the extraction process. ${ }^{5-7}$ The potential of viral lysis buffer for SARS-CoV-2 RNA stabilization at varying temperatures and periods of time remains unknown. To find a practical solution, we evaluated the stability of SARS-CoV-2 RNA in viral lysis buffer of RNA extraction at

(C)2020. The Indian Association of Laboratory Physicians.

This is an open access article published by Thieme under the terms of the Creative Commons Attribution-NonDerivative-NonCommercial-License, permitting copying and reproduction so long as the original work is given appropriate credit. Contents may not be used for commercial purposes, or adapted, remixed, transformed or built upon. (https://creativecommons.org/licenses/by-nc-nd/4.0/).

Thieme Medical and Scientific Publishers Pvt. Ltd. A-12, 2nd Floor, Sector 2, Noida-201301 UP, India 
two different temperature conditions by testing specimens on different time periods.

\section{Materials and Methods}

SARS-CoV-2 positive samples $(n=20)$ having Ct values ranging from 16 to 35 were selected for this evaluation. The study was conducted primarily using viral lysis buffer of HiPurA Viral RNA purification kit (Himedia, Mumbai, India); also, the following commercial RNA extraction kits were used for further evaluation (i) Invitrogen Purelink RNA Mini Kit (Invitrogen, USA), (ii) QIAamp Viral RNA Mini Kit (Qiagen, USA) and (iii) TRUPCR COVID-19 Viral RNA Extraction kit (TRUPCR, India).

All the selected positive samples were processed parallelly in two sets of HiPurA Viral RNA viral lysis buffer as per manufacturer's instruction. Briefly, $140 \mu \mathrm{L}$ aliquots of the sample were added to $1.5 \mathrm{~mL}$ microcentrifuge tubes preloaded with aliquots of the freshly prepared viral lysis buffer $(560 \mu \mathrm{L})$, carrier RNA $(5.6 \mu \mathrm{L})$ and MS2 phage control $(10 \mu \mathrm{L})$. On the other hand, $140 \mu \mathrm{L}$ samples were kept in two parallel sets of vials without addition of viral lysis buffer along with carrier RNA and MS2 phage control. For the quality control aspect, MS2 phage control was used as an internal process control of RNA extraction and the no lysis buffer control was used for the comparison of samples added in lysis buffer.

All the prepared viral lysis buffer suspension and no lysis buffer vials were kept at two different temperature conditions: refrigerator $\left(2-8^{\circ} \mathrm{C}\right)$ and ambient temperature $\left(22-28^{\circ} \mathrm{C}\right)$ for 24 hours, 48 hours and 72 hours separately. Thereafter, RNA was extracted from each of the experimental vials (samples suspensions [710 $\mu \mathrm{L}]+$ ethanol [560 $\mu \mathrm{L}]$ ) using HiPurA Viral RNA purification kit (Himedia, Mumbai, India).

The integrity of extracted viral RNA was evaluated by multiplex real-time RT-PCR test for the qualitative detection of RNA from SARS-CoV-2 using TaqPath RT-PCR COVID-19 kit (Applied Biosystems, CA, USA). This multiplexed assay contains three primer/probe sets specific to different SARS-CoV-2 genomic regions (orf-1ab gene, gene for the $\mathrm{S}$ protein and gene for the $\mathrm{N}$ protein) and primers/ probes for bacteriophage MS2. The assay was performed on the QuantStudio 7 Pro Real-Time PCR System (Applied Biosystems, CA, USA). Samples with discrepant results were retested in duplicate. Furthermore, the same experiment was performed using the three other commercially available RNA extraction kits to determine their performance characteristics in protecting the viral RNA. The data were expressed as the mean \pm standard deviation (SD) and analyzed using MS Excel 2010.

\section{Results}

Mean and standard deviation of the $\mathrm{Ct}$ value of the three tested genes were calculated for the analysis of the results. The variation of $\mathrm{Ct}$ values at 24 hours and 48 hours was found to be in the accepted range of one SD interval of the initial testing $\mathrm{Ct}$ values (-Table $\mathbf{1}$ ). This indicates an unchanged quantity of SARS-CoV-2 viral RNA at 24 hours and 48 hours in both the temperatures. However, all the tested samples showed 1 or $2 \mathrm{Ct}$ reduction after incubation in lysis buffer for 24 hours in both the storage conditions. At 2 to $8^{\circ} \mathrm{C}$, SARS-CoV-2 viral RNA was relatively more stable than room temperature storage. Decline in the viral RNA quantity was observed in the samples stored up to 78 hours in both the temperature conditions and $60 \%$ samples turned to be negative. No significant difference in the stability of orf- $1 a b, N$ gene and $S$ gene was noted. All three gene targets were found within the accepted range for up to 48 hours storage in both the temperatures. Samples placed in no lysis buffer did not show positive results. Lysis buffers of other three commercially available RNA extraction kits showed almost the similar results (data not shown).

\section{Discussion}

The use of viral lysis buffers to stabilize viral RNA has been investigated for viruses other than SARS-CoV-2.5-7 For the first time, the present study investigated the potential of viral lysis buffer to stabilize SARS-CoV-2 virus RNA at varying temperatures and periods of time. Previous studies on other viruses established viral RNA integrity in viral lysis buffer kept at $20^{\circ} \mathrm{C}, 4^{\circ} \mathrm{C}$ and $25^{\circ} \mathrm{C} .{ }^{6,8}$

The study included 20 SARS-CoV-2 positive samples having both the lower $\mathrm{Ct}$ values $(n=10)$ and higher $\mathrm{Ct}$ values $(n=10)$ (Ct values ranging from 16 to 35$)$. These known positive samples were lysed in parallel using viral lysis buffers and stored separately at 2 to $8^{\circ} \mathrm{C}$ and 22 to $28^{\circ} \mathrm{C}$ for 24 hours, 48 hours and 72 hours. This study showed the integrity and reproducibility of positivity in all the samples included in this study. The internal control MS2 phage was also demonstrated in all experimental setups.

The SARS-CoV-2 RNA remained intact in samples for at least 48 hours at 2 to $8^{\circ} \mathrm{C}$ and 22 to $28^{\circ} \mathrm{C}$. Our results showed a significant correlation of initial testing $\mathrm{Ct}$ values of orf- $1 a b$,

Table 1 Stability of SARS-CoV-2 RNA on viral lysis buffer after a period of storage at different temperatures

\begin{tabular}{|c|c|c|c|c|c|c|c|}
\hline \multirow{2}{*}{\multicolumn{2}{|c|}{$\begin{array}{c}\text { Storage temperature } \\
\text { Storage period }\end{array}$}} & \multicolumn{3}{|c|}{$2-8^{\circ} \mathrm{C}$} & \multicolumn{3}{|c|}{$22-28^{\circ} \mathrm{C}$} \\
\hline & & $24 \mathrm{~h}$ & $48 \mathrm{~h}$ & $72 \mathrm{~h}$ & $24 \mathrm{~h}$ & $48 \mathrm{~h}$ & $72 \mathrm{~h}$ \\
\hline SARS-CoV-2 gene & $\begin{array}{l}\text { Initial Ct value } \\
\text { (mean and SD) }\end{array}$ & \multicolumn{6}{|c|}{$\begin{array}{l}\text { Ct values } \\
\text { (mean) }\end{array}$} \\
\hline orf-1ab gene & $25.5( \pm 9.50)$ & 26.22 & 28.63 & 32.80 & 27.30 & 29.15 & 35.54 \\
\hline Sgene & $26.8( \pm 6.85)$ & 27.45 & 28.74 & 30.42 & 28.42 & 30.12 & 34.21 \\
\hline N gene & $27( \pm 5.10)$ & 28.01 & 30.28 & 31.51 & 29.3 & 31.41 & 33.9 \\
\hline
\end{tabular}


$N$ gene and $S$ gene of known SARS-CoV-2 sample compared with the experimental setup samples. Slight RNA degradation was observed in samples stored at 22 to $28^{\circ} \mathrm{C}$ as compared with samples stored in the refrigerator at 2 to $8^{\circ} \mathrm{C}$.

The study included 10 samples with borderline $\mathrm{Ct}$ values, in which two samples had Ct 35 for orf-1ab gene. All these borderline $\mathrm{Ct}$ values samples showed positive results when stored up to 48 hours. According to TaqPath multiplex RT-PCR COVID-19 kit protocol, any of the two genes within Ct value of 36 and with the sigmoid amplification curve will be considered as a positive. In this study, two samples with higher $\mathrm{Ct}$ value of 35 (for orf-1ab gene) showed $4 \mathrm{Ct}$ reduction after incubation in lysis buffer for 48 hours. However, these two samples were considered positive, as the other two genes ( $N$ gene and $S$ gene) were in acceptable range and these samples turned negative after 72 hours incubation.

Higher variations in Ct values were also observed in samples stored for 72 hours' time period at both temperatures. We did not further analyze samples for longer durations (more than three days), as in this pandemic situation, delayed testing and reporting seems worthless.

No positive results were observed from no lysis buffer controls and some were failed in the RNA extraction procedure, as the internal MS2 phage control did not amplify in PCR. Viral lysis buffers mainly contain chaotropic agents such as guanidine thiocyanate (GITC) or other protein denaturants, which are sufficient to render viruses noninfectious by their denaturing activity. Hence, samples without viral lysis buffer will not remain suitable for diagnosis.

RNA extraction is a crucial step in the detection of SARS-COV-2 and the result outcome depends upon the performance of the RNA extraction kit used. Different laboratories are using different kits, and the kits are being changed very frequently, especially during the current COVID-19 crisis. Hence, this study also evaluated other three commonly used commercial RNA extraction kits for the ability to protect viral RNA. There was no major difference in the $\mathrm{Ct}$ values, and all the kits showed almost similar results by stabilizing RNA up to 48 hours.

The main purpose of this study was to evaluate the stability of SARS-CoV-2 viral RNA and to evaluate the reproducibility and not to assess the quality and quantity of the viral RNA.

\section{Conclusion}

In the recent emergence of SARS-CoV-2, testing laboratories are currently witnessing increased sample load every day. Viral lysis buffer turns sample to be noninfectious and provides stabilization of SARS-CoV-2 RNA for up to 48 hours even at room temperature. This allows laboratories to maintain continuous workflow of sample processing and testing without compromising timeliness and storage of samples.

\section{Conflicts of Interest}

None declared.

\section{Acknowledgment}

We would like to acknowledge Dr Arvind Rai, Ex Joint Director \& Head, Division of Biotech \& Molecular Diagnostics, National Centre for Disease Control, Delhi for his fruitful discussions and suggestions. We would also like to thank Mr. Kamalesh K Ahirwar, Technical Assistant, for his assistance.

\section{References}

1 Lai CC, Shih TP, Ko WC, Tang HJ, Hsueh PR. Severe acute respiratory syndrome coronavirus 2 (SARS-CoV-2) and coronavirus disease-2019 (COVID-19): The epidemic and the challenges. Int J Antimicrob Agents 2020;55(3):105924

2 Sohrabi C, Alsafi Z, O'Neill N, et al. World Health Organization declares global emergency: A review of the 2019 novel coronavirus (COVID-19) Int J Surg 2020;76:71-76

3 van Kasteren $\mathrm{PB}$, van der Veer B, van den Brink S, et al. Comparison of seven commercial RT-PCR diagnostic kits for COVID-19. J Clin Virol 2020;128:104412

4 Scallan MF, Dempsey C, Mcsharry J, O'callaghan I. Validation of a lysis buffer containing $4 \mathrm{M}$ Guanidinium validation of a lysis buffer containing $4 \mathrm{M}$ Guanidinium Thiocyanate (GITC)/Triton $\mathrm{X}-100$ for extraction of SARS-CoV-2 Thiocyanate (GITC)/ Triton X-100 for extraction of SARS-CoV-2. bioRxiv 2020 (e-pub ahead of print). doi: https://doi.org/10.1101/2020.04.05.026435

5 Amellal B, Murphy R, Maiga A, et al. Stability of HIV RNA in plasma specimens stored at different temperatures. HIV Med 2008;9(9):790-793

6 Liu H, Gan Y, Wu Y, Weng H, Lei P, Shen G. Effects of different lysis buffers of nucleic acid purification kit on the stability of influenza virus RNA. Future Virol 2014;9(6):549-555

7 Ngo KA, Jones SA, Church TM, et al. Unreliable inactivation of viruses by commonly used lysis buffers. Appl Biosaf 2017;22(2):56-59

8 Anwar A, Wan G, Chua K. et al. Evaluation of pre-analytical variables in the quantification of dengue virus by real-time polymerase chain reaction. Available at: https://www.sciencedirect.com/science/article/pii/S1525157810602760. Accessed May 24, 2020 